\title{
Correction to: If You Detonate Dynamite, You Should Know Your
} Fish

\section{Dietrich Doll ${ }^{1,2}$}

\section{Correction to: World J Surg}

https://doi.org/10.1007/s00268-017-3971-1

In the original article, the last paragraph erroneously states that the author's upcoming study was going to be published in Diseases of the Colon and Rectum.
The study was published in World Journal of Surgery:

Bosche F, Luedi MM, van der Zypen D et al. (2017) The hair in the sinus: sharp-ended rootless head hair fragments can be found in large amounts in pilonidal sinus nests. World J Surg. https://doi.org/10.1007/s00268-017-4093-5.

The original article can be found online at https://doi.org/10.1007/ s00268-017-3971-1.

Dietrich Doll

ddoll@gmx.de

1 St. Marienhospital Vechta, Procto-Surgery, Vechta, Germany

2 Medical School, Department of Surgery, University of the Witwatersrand, Johannesburg, South Africa 